\title{
A reprodução do estigma na insolvência das famílias
}

The Reproduction of the Stigma of Household Insolvency

La reproduction du stigma de l'insolvabilité des ménages

Catarina Frade e Ana Filipa Conceição

\section{OpenEdition}

Journals

Edição electrónica

URL: http://journals.openedition.org/rccs/5396

DOI: $10.4000 /$ rccs.5396

ISSN: 2182-7435

\section{Editora}

Centro de Estudos Sociais da Universidade de Coimbra

\section{Edição impressa}

Data de publição: 1 setembro 2013

Paginação: 135-152

ISSN: 0254-1106

Refêrencia eletrónica

Catarina Frade e Ana Filipa Conceição, «A reprodução do estigma na insolvência das famílias», Revista Crítica de Ciências Sociais [Online], 101 | 2013, posto online no dia 17 fevereiro 2014, consultado o 04 fevereiro 2021. URL: http://journals.openedition.org/rccs/5396 ; DOI: https://doi.org/10.4000/rccs. 5396 


\section{CATARINA FRADE ANA FILIPA CONCEIÇÃO}

\section{A reprodução do estigma na insolvência das famílias}

O crédito não trouxe apenas uma antecipação do rendimento das famílias, permitindo-lhes antecipar o consumo de diversos bens. Também fez aumentar a sua vulnerabilidade a acontecimentos pessoais ou contextuais que comprometem o seu equilíbrio financeiro e o pagamento das suas dívidas. Tal como no passado, o direito procurou, através dos dispositivos legais da falência, proporcionar uma via de saída para os indivíduos e as famílias excessivamente onerados por dívidas que não conseguem solver. Mas tal como no passado, o direito da falência não deixou de reproduzir nos seus dispositivos legais, e no modo como estes são aplicados, parte da atitude estigmatizante e censuradora que por séculos tem acompanhado os falidos. Pelo contrário, tem-se servido do próprio estigma para reforçar a sua eficácia e desestimular a utilização generalizada deste processo, tentando preservar um padrão comportamental onde prevalece a honorabilidade dos compromissos assumidos.

Palavras-chave: direito falimentar; discriminação; estigma (psicologia social); finanças pessoais; insolvência.

\section{Introdução}

"As falências pessoais estão a aumentar porque os americanos perderam o sentimento da vergonha." Foi com esta afirmação que Alan Greenspan, na altura presidente da Reserva Federal Norte-americana, se dirigiu ao Congresso, em 1999, quando se iniciaram os trabalhos de revisão do Código de Falência dos Estados Unidos da América (EUA). ${ }^{1}$

Com uma precisão desarmante, esta declaração de um alto dirigente político norte-americano condensa séculos de discursos penalizadores e moralistas em torno da falência e dos falidos.

\footnotetext{
${ }^{1}$ Neste texto, os termos insolvência e falência, assim como insolvente e falido, são tomados como
} sinónimos entre si. 
Muito se tem escrito e dito sobre a falência: as suas causas, as suas consequências, as suas vantagens, os seus inconvenientes. Este texto pretende trazer uma análise focada não tanto na falência em si, mas na dialética que nela se pode descobrir entre o direito e o estigma. Uma dialética que, ao arrepio da interpretação virtuosa de que o direito é um instrumento privilegiado no combate ao estigma e à discriminação, se consubstancia numa utilização viciosa do rótulo pejorativo de falido para promover a própria conformação dos comportamentos individuais com o direito, mormente com o direito dos contratos.

Partindo de uma análise sucinta da relação entre direito e estigma, mostrar-se-á como o direito falimentar foi, desde o início até ao momento atual, em vários países e em Portugal, um terreno fértil para a promoção de uma cultura estigmatizante em torno dos indivíduos que, por incapacidade de pagar as suas dívidas, encontram na falência uma solução de último recurso.

\section{A abordagem do direito ao estigma: prevenção e promoção}

O estigma, conforme o entendimento de Erving Goffman (1963), traduz-se num processo por meio do qual a reação dos outros (os não estigmatizados a que o autor se refere como os "normais") a um determinado traço físico, de carácter ou de cultura de uma pessoa que a impede de construir uma identidade social normal. O estigma constitui um rótulo pejorativo que é associado a uma pessoa ou a um grupo e que lhes provoca um sentimento de vergonha. A vergonba é o estado interior do estigmatizado, afirma Friedman (1975).

Enquanto estereótipo negativo, o estigma pode transmutar-se em discriminação, ou seja, num comportamento injusto face a um indivíduo ou a um grupo que resulta precisamente daquele estereótipo negativo (Canadian Mental Health Association, 2013). Mas para que o estigma ocorra verdadeiramente é necessário que o estigmatizado reconheça essa personalidade desconforme como uma realidade (visibilidade do estigma) (Burris, 2008). O estigma pressupõe por isso a existência de uma norma e de um desvio à norma, acompanhados do reconhecimento pelos sujeitos (estigmatizados e não estigmatizados) dessa desconformidade face à norma instituída. A produção do estigma e o seu reconhecimento estão associados ao poder, como defendem Link e Phelan (2006): é necessário ter poder para ser capaz de estigmatizar. O estigma só resulta quando se registam diferenças de poder entre estigmatizados e não estigmatizados, em desfavor daqueles.

De acordo com Burris (2006), o direito interfere com a operacionalização do estigma na sociedade de três maneiras. Por um lado, o direito atua 
na prevenção do estigma e/ou na reparação dos danos por ele causados. Por outro lado, o direito apoia o combate do indivíduo estigmatizado, proporcionando-lhe meios específicos para lutar contra a discriminação de que é alvo. Finalmente existe uma terceira abordagem do direito ao estigma por meio da qual o estigma é criado ou imposto pelo próprio direito.

O discurso sobre a interação entre o direito e o estigma centra-se preferencialmente nas primeiras duas perspetivas, pois elas afiguram-se mais consonantes com o próprio referencial de justiça que torna a ordem jurídica um sistema normativo amplamente reconhecido. O direito transporta consigo uma importante função normalizadora da sociedade e da atuação que nela devem assumir os indivíduos. Essa normalização de comportamentos sociais radica numa escala de valores comummente aceite e reconhecida pela sociedade e pelos seus membros, na qual prontificam, no mundo ocidental, os valores da dignidade da pessoa humana, da igualdade e da não discriminação.

É com base nesses fundamentos axiológicos que se concebem normas jurídicas e instrumentos processuais que procuram suprimir ou suprir comportamentos discriminatórios decorrentes de aspetos negativos atribuídos a indivíduos ou grupos de indivíduos. A começar pelo patamar constitucional, no caso português, que contém um princípio geral de proibição de qualquer discriminação baseada em características pessoais ou convicções políticas e religiosas. Segue-se uma miríade de medidas configuradas na lei e vertidas na atuação dos poderes públicos, que estabelecem formas de integração no mercado de trabalho, na vida social e política, e na economia de indivíduos ou grupos mais vulneráveis e, por isso, mais expostos a atitudes discriminatórias e comportamentos excludentes. E para a sua efetividade existem dispositivos coercivos e sancionatórios que proporcionam uma reparação dos danos sofridos pelos indivíduos discriminados e uma punição dos autores dessa discriminação. ${ }^{2}$ Não é, porém, esta interface entre o direito e o estigma que se pretende discutir aqui. Ao invés, procura-se explorar o modo como o direito potencia e se aproveita do estigma para reforçar a sua efetividade na sociedade, tomando como exemplo muito particular o direito falimentar.

Há muito que se reconhece existir no direito criminal uma utilização do estigma como fator de afirmação da validade e da coercibilidade do próprio direito (Galbiati e Garoupa, 2007; Braithwaite, 1989). ${ }^{3}$

\footnotetext{
${ }^{2}$ Os debates em torno do estigma são comuns nas questões de saúde, designadamente nas áreas da doença mental e do HIV. São igualmente frequentes nas questões de género e de raça ou nos estudos dedicados a minorias.

${ }^{3}$ Consultar Mols (2012) e as referências aí mencionadas a estudos na área da criminologia sobre o impacto e a importância do estigma no direito penal.
} 
A vergonha associada à punição é conscientemente utilizada para fortalecer a coesão social e manter a conformidade com a norma, sobretudo quando à pena criminal se associam outras medidas de cariz igualmente punitivo. A publicitação de certas condenações ou a criação de registos públicos para certos tipos de crimes (o caso dos predadores sexuais nos EUA ou a lista dos incumpridores em matéria tributária, em Portugal) são medidas punitivas acessórias associadas a certos ilícitos que, ao reforçarem o sentimento de vergonha que a pena em si mesma já comporta, criam também uma pressão acrescida sobre os culpados para que não reincidam e procurem conformar-se com a norma vigente (prevenção especial). ${ }^{4}$ Ao mesmo tempo, servem para fazer destes casos exemplos para a sociedade, quer no sentido de prevenir comportamentos semelhantes de outros indivíduos, quer para dar sinais à vítima e à comunidade em geral de que as normas penais são respeitadas e que as instituições que as aplicam têm meios para as fazer respeitar (prevenção geral). Alguns autores, como Nussbaum (2004) e Burris (2008), apesar de reconhecerem algum benefício nestas práticas, não deixam de as criticar, argumentando, entre outras coisas, que punições vexatórias podem trazer ao de cima o pior da sociedade, ao promoverem a humilhação coletiva e o ostracismo de indivíduos ou de certos grupos. Em Portugal, Figueiredo Dias também advoga que "deve pelo menos exigir-se incondicionalmente que não seja a própria lei a contribuir para a estigmatização que já acompanha por si mesma a pena criminal." (1983:33-34). Dando corpo a esta ideia, o penalista defende um acesso muito restrito ao registo criminal dos indivíduos e o fim de uma conexão necessária entre pena e perda de direitos civis, profissionais ou políticos (ibidem: 36).

A propugnação por uma utilização muito limitada ou mesmo nula destas medidas através das quais se faz a reafirmação da força do direito pela promoção do estigma e da vergonha não é, todavia, simples, para mais num tempo em que o Estado carece de recursos financeiros, materiais e humanos para executar a sua função coercitiva. É que, como reconhece Nussbaum (2004), o recrudescimento do interesse por punições vexatórias que se vem observando é atrativo para o Estado, na medida em que produz efeitos dissuasores visíveis a custos reduzidos ou mais reduzidos dos que os que resultam da efetivação por exemplo da pena de prisão.

\footnotetext{
${ }^{4}$ À sanção em direito penal atribuem-se determinadas finalidades: evitar comportamentos ilícitos semelhantes por parte de outros indivíduos, através da reafirmação da validade das normas jurídicas violadas (prevenção geral); e impedir a reincidência do culpado ajudando-o a reintegrar-se novamente na sociedade (prevenção especial). Mais contestada é a ideia de que a pena tem igualmente uma finalidade retributiva, de providenciar uma certa compensação da vítima pelo mal sofrido através da produção de um mal ao delinquente (cf. Antunes, 1993; Dias, 1983).
} 
Mas o direito criminal não é o único domínio do jurídico onde a questão do estigma avulta com alguma acuidade. Friedman (1975) já havia reconhecido que na área do direito cível, nomeadamente nos regimes do divórcio e da falência, o estigma também estava presente e servia os propósitos da reafirmação da sua força jurídica.

A sociedade tende a ser menos tolerante com os comportamentos desconformes que são considerados da responsabilidade do indivíduo (como o divórcio ou a falência), do que com aqueles que ele não pode controlar (Efrat, 2006b). O estigma pode subsistir em face de determinados comportamentos, independentemente de serem controláveis ou não pelo seu autor, mas enquanto os primeiros geram uma antipatia declarada, os segundos suscitam alguma compaixão (Mols, 2012). A imputação de responsabilidades é maior perante factos controláveis e essa distinção é vulgarmente refletida na lei, nomeadamente em sede de apreciação da culpa do acusado ou, como sucede no caso da falência, nos termos exigidos para o perdão das dívidas remanescentes e não pagas com o produto da liquidação do património do falido (a exoneração do passivo restante prevista para os indivíduos no Código da Insolvência português).

O direito falimentar adotou desde sempre uma postura quasi-criminalizadora do falido, considerando-o moralmente responsável por se ter desviado, de moto proprio, de um comportamento de honorabilidade e honestidade no cumprimento das suas obrigações contratuais. ${ }^{5}$

As relações económicas de base de mercado encontram no princípio da pacta sunt servanda (os contratos são para se cumprir) o seu pilar de sustentação (Reifner et al., 2003). Ao declararem falência, os indivíduos falham em proceder de acordo com a norma dominante e comprometem o funcionamento do próprio mercado, quebrando uma promessa e a confiança do credor. Este princípio há muito incrustado na generalidade das ordens jurídicas combina preocupações do foro moral com exigências de segurança jurídica e com a proteção de interesses económicos que garantem o regular funcionamento das instituições mercantis. No respaldo do livre funcionamento da economia e da autonomia privadas, o seu grau de tolerância a medidas de exceção tende a ser reduzido. Possibilidades que escapam à regra da força obrigatória das convenções ou dos contratos, como sejam o perdão das dívidas ao abrigo do regime da falência ou o reajuste

\footnotetext{
5 Segundo Carlsson e Hoff (2000: 309), a prova do merecimento do perdão de dívidas que está consagrada em várias leis europeias da falência ilustra a função de coesão social que Durkheim atribui à pena. Por sua vez White (2007: 3) esclarece que o desencorajamento dos faltosos pela punição que representa ser declarado falido é ainda um dos propósitos atuais do direito falimentar.
} 
dos termos contratuais à luz da teoria da imprevisão (consagrada através do princípio da rebus sic stantibus) ou da figura do abuso do direito (cf. artigo 334. ${ }^{\circ}$ do Código Civil) são sempre encaradas com reserva e tratadas com cautela tanto pelo direito positivo, como pela prática jurisprudencial. ${ }^{6}$

Não obstante, a atuação do próprio mercado, com os seus efeitos adversos, acabou por impor a presença destes mecanismos de reequilíbrio de poder entre os contraentes. A expansão do consumo e do crédito às famílias levou muitos países a criarem respostas específicas para os casos de incumprimento e sobreendividamento, baseados num alívio das condições contratuais e numa eliminação total ou parcial das suas dívidas (Frade, 2007).

A adoção de soluções extrajudiciais ou judiciais baseadas na renegociação de planos de pagamento com os credores combinou-se com o processo de falência, vocacionado para os devedores com poucas ou nenhumas expectativas de obterem um rendimento estável ou de o aumentarem. Para aqueles que possuem emprego ou meios financeiros capazes de pagar boa parte das dívidas e que desejam proteger os seus bens, nomeadamente a habitação familiar, a renegociação de um plano de pagamentos dentro ou fora do tribunal (com o apoio ou não de gabinetes especializados no apoio a sobreendividados) oferece, entre outras vantagens, um maior controlo do processo pelos próprios devedores e uma menor exposição pública das suas dificuldades (menor estigma, portanto), já que não existe qualquer publicidade associada.

Ao invés, e como se verá com maior detalhe adiante, para aqueles que não possuem meios de subsistência suficientes nem perspetivas de melhoria dos mesmos a breve trecho, resta-lhes peticionar falência e suportar a perda dos bens de cuja venda se espera obter algum ressarcimento a favor dos credores. Depois terão ainda de esperar cinco anos para saberem se serão ou não agraciados com um perdão das dívidas remanescentes. Durante esse tempo, deverão entregar ao tribunal o que exceda o mínimo de rendimento que lhes foi fixado para viver e comportar-se como "pessoas de bem" para serem considerados merecedores daquele perdão.

\footnotetext{
${ }^{6}$ Pela sua excecionalidade no panorama judicial português ficou célebre uma sentença proferida pelo juiz de primeira instância do Tribunal de Portalegre, em janeiro de 2012, quando, invocando a figura do abuso do direito, considerou extinto um crédito à habitação pela entrega da casa à instituição bancária e negou ao banco o direito de exigir o valor em dívida que resultou da diferença entre a avaliação do imóvel no momento da retoma (valor inferior) e a do momento do contrato (valor superior) (decisão publicada em http://www.inverbis.pt/2012/ficheiros/doc/ tribunalportalegre_creditohipotecario.pdf). Logo depois, porém, o Tribunal da Relação de Lisboa, num caso com algumas semelhanças, veio contrariar a argumentação expendida pelo Tribunal de Portalegre (Acórdão TRL n. ${ }^{\circ}$ 1417/08.8TCSNT.L1-2).
} 
Punição, falta, merecimento e perdão são, por isso, termos que há muito combinam com o direito falimentar e que mostram de forma exemplar como este domínio do jurídico soube tirar proveito de uma atitude estigmatizadora dirigida aos falidos para se afirmar em pleno. Ontem, como hoje, a falência oferece um campo de análise profícuo para o estudo do estigma e da sua instrumentalização pelo direito.

Nos pontos que se seguem ilustrar-se-á em detalhe essa interação entre o direito falimentar e a promoção do estigma, desde tempos remotos até à realidade portuguesa atual.

\section{A configuração do estigma no direito falimentar: resenha histórica e experiências comparadas}

A falência ou insolvência, enquanto instituto jurídico, surgiu como uma necessidade imperiosa do progresso económico e foi, durante largo tempo, reservada aos comerciantes.

A sua história é pontuada de vários momentos seminais. A total ausência nas sociedades primitivas dá lugar ao reconhecimento de um processo de execução coletiva por dívidas acessível a todos quantos se achavam impossibilitados de as pagar. A par desse reconhecimento normativo emergiu uma valorização cultural e religiosa profundamente negativa e estigmatizante dos devedores insolventes. Essa censura pública sublimava-se na execução dirigida à pessoa do devedor e à sua família. Ao longo do tempo, porém, o animus retaliatório foi cedendo ao princípio da compensação e a falência dos comerciantes começou a autonomizar-se e a merecer maior aceitação social, ao mesmo tempo que a execução contra o devedor foi sendo progressivamente substituída pela execução contra o seu património (Frade, 2012).

O desenvolvimento económico e o capitalismo comercial consolidaram jurídica e culturalmente a falência das empresas, mas os indivíduos continuaram reféns das suas dívidas, sujeitos à vindicta dos credores e à aplicação de sanções vexatórias e draconianas. Cinco séculos separam o aparecimento do direito da falência das empresas (século XIV) da dos indivíduos (século XIX). ${ }^{7}$

De acordo com Levinthal (apud Tabb, 2002: 5), a falência foi desde os primórdios norteada por dois objetivos principais: garantir uma distribuição

\footnotetext{
${ }^{7}$ O Código da Falência norte-americano de 1841 admitiu pela primeira vez a falência de não comerciantes e a falência voluntária, ou seja, requerida pelo próprio devedor (McCoid, apud Tabb, 2002: 142). É, no entanto, o Código da Falência de 1898 que emerge como o primeiro regime de falência assumidamente pró-devedor, ao permitir a liquidação com o perdão imediato de dívidas para as pessoas singulares (Ziegel, 2006: 313).
} 
equitativa da propriedade do devedor por todos os seus credores e evitar comportamentos do devedor lesivos dos interesses económicos dos credores. "O direito da falência procura proteger os credores, primeiro, uns dos outros, e segundo, do seu devedor." Por sua vez, Jackson e Scott (apud Tabb, 2002: 85) veem no processo de falência a "... maximização do bem-estar de um grupo - os credores - através da coletivização...” do risco de quebra de um devedor e da insuficiência de património.

Para Charles Tabb (2005: 2), todas as sociedades partiram do mesmo ponto: de que os devedores faltosos são pessoas más e desonestas, que por isso merecem ser punidas severamente e tratadas com aspereza, sem direito a perdão e a compaixão.

No seu artigo "The Evolution of Bankruptcy Stigma”, Rafael Efrat (2006a) faz uma síntese histórica das sevícias e dos aviltamentos que, durante vários séculos e em várias civilizações, foram aplicados aos insolventes. Das antigas civilizações grega e romana, passando pela Índia, até à Europa Ocidental e aos Estados Unidos, sobressai uma atitude persistente de repúdio dos que, seja por que razão for, não cuidaram de honrar os seus contratos.

O autor apresenta duas razões para esta estigmatização a que os insolventes se acharam votados desde sempre (ibidem: 368). A primeira razão deve-se ao facto de o devedor que declara falência assumir um comportamento desviante em relação à moral social, que impõe o respeito pelos demais membros da sociedade, nomeadamente pelos credores que nele confiaram. Deste modo, o devedor insolvente adota uma conduta fraudulenta e negligente, incumprindo o seu dever moral de pagamento das dívidas contraídas. ${ }^{8}$ A segunda razão prende-se com o recurso ao crédito em si mesmo: a falência exprime o insucesso do devedor na gestão financeira da sua vida ou dos seus negócios, pelo facto de ele ter sido demasiado ambicioso e ter contratado crédito, em vez de se ater simplesmente aos seus recursos.

Atributos como fraude, excesso, má-fé e desrespeito pelas normas sociais vigentes estão historicamente associados à falência, provocando o desagrado social pelo processo e pelos seus utilizadores e conduzindo a uma criminalização dos falidos. Os mecanismos de falência e de cobrança de dívidas foram concebidos com o desígnio de provocar o rebaixamento e o desprestígio dos devedores.

Nas culturas pré-modernas, a marginalização social do falido, através da degradação pública e da criminalização, serviu para desestimular o recurso ao crédito e manter a coesão social. A exibição em praça pública

\footnotetext{
${ }_{8}^{8}$ No preâmbulo do primeiro Código da Falência inglês (1543), o devedor falido era descrito como um ser antissocial, imoral e que apenas se aproveitou dos demais (Martin, 2005: 36).
} 
ao escárnio dos seus pares (Índia primitiva), com uma cesta na cabeça (Grécia Antiga), enquanto eram leiloados como escravos pelos credores (Roma) ou forçados a sentar numa pedra negra (cidades pré-italianas), ${ }^{9}$ coexistia com a amputação do corpo (Índia, Grécia, Roma e Pérsia), a perda da liberdade e da honra (Egito, Grécia, Roma), da família (Grécia e Roma) e da própria vida (Frade, 2012).

Nos séculos seguintes, a situação não se alteraria grandemente e a penalização social e jurídica mantinha-se forte. Em 1490, o direito francês impunha que o falido se apresentasse nu perante o juiz. Já no século XIX, os comerciantes falidos ficavam praticamente inibidos de quaisquer atos de comércio até pagarem a totalidade do que deviam (uma espécie de capitis diminutio). Em Inglaterra, além da prisão, era possível o enforcamento por dívidas, até ao ano de $1820 .^{10}$

$\mathrm{Na}$ primeira fase da colonização da América, os falidos eram encarados com alguma compreensão pela sociedade que então se estava a formar. A isso não será porventura alheio o facto de muitos terem partido à procura de uma nova oportunidade para recomeçar, escapando a uma pesada herança de dívidas na Europa (Marques, 2000: 215). Contudo, a necessidade de estruturar e manter coesas as comunidades que se iam formando levou a uma importação da moral puritana europeia, da qual fazia parte a estigmatização social dos falidos. Da exibição em praça pública, passando pelo corte do cabelo ou de uma orelha, pela marcação a ferro da letra T (de thief, isto é, ladrão) na palma da mão, até à perda da liberdade, os colonos americanos mantiveram-se fiéis às suas origens culturais e religiosas. Só a partir de 1820 é que alguns Estados americanos aboliram a prisão por dívidas (reservando-a eventualmente para os casos de fraude), enquanto a abolição completa só chegaria um século mais tarde.

O estigma imputado aos devedores onerados por dívidas continuou já depois do século XIX. ${ }^{11}$ Sobressai o caso irlandês, em que o devedor que

\footnotetext{
9 Em Pádua, Itália, no Palazzo della Ragione, a "pedra da vergonha ou do vitupério" serviu para, durante a Idade Média, nela serem exibidos nus os falidos, antes de serem exilados.

${ }_{10}$ A obra de Charles Dickens, Little Dorrit (1857), é um excelente exemplo de como a questão da falência chegou até à literatura inglesa da época vitoriana. Little Dorrit é uma jovem nascida em Marshalsea, uma prisão para devedores na qual o seu pai estava encarcerado e para a qual se mudara toda a família. Na sociedade inglesa de então, o falido era visto e tratado como um leproso e a prisão era o seu lazareto (Martin, 2005: 37).

${ }^{11}$ Esta estigmatização repercute-se no próprio mercado do trabalho, com os sobreendividados a acabarem despedidos quando o empregador é confrontado com a penhora do salário. O empregador, afirma Haas (2006: 15), tende a encarar a penhora da retribuição do trabalhador como prova de uma vida desequilibrada e instável e que acabará por ter efeitos negativos na qualidade do seu trabalho. Essa realidade está documentada para alguns países (ASB, 2004). Consultar, também, para o caso norte-americano, Thorne e Anderson, 2006.
} 
falhava no cumprimento de um acordo judicial de reescalonamento de dívidas incorria numa pena de prisão até noventa dias. Assim foi até 2009, altura em que o Supremo Tribunal considerou esta prática inconstitucional. ${ }^{12}$ Por ano, cerca de duzentos devedores eram encarcerados à luz deste regime anacrónico e vexatório.

Nathalie Martin (2005: 39) recorda que só com o Código da Falência de 1978 a lei americana substituiu a dura expressão falido pela mais branda de devedor. Estudos vários realizados nos EUA (Porter, 2010; Sullivan et al., 2000) referem o sofrimento sentido pelos falidos e dão conta dos esforços que estes fazem para esconder de todos a sua condição, que consideram no mínimo embaraçosa e no pior caso devastadora.

O valor explicativo da estigmatização social na evolução do direito da insolvência tem um significado particular no caso americano. A liberalização dos costumes na década de sessenta e o forte crescimento económico provocaram um aumento significativo do número de processos de falência nos tribunais. $\mathrm{O}$ facto levou as instituições credoras a advogar uma maior restritividade do regime falimentar, para evitar o seu uso abusivo que resultara do que afirmavam ser uma diminuição da censura social em torno dos falidos (Ziegel, 2006: 313). ${ }^{13}$ A sua posição não vingaria na revisão de 1978 do Código da Falência, mas foi bem-sucedida na revisão de 2005 (Warren, et al., 2006).

O tema da cultura e da estigmatização social tem alimentado um longo e intenso debate na sociedade americana, desde os anos 60 do século Xx. A revisão de 2005 provocou uma nova torrente de artigos científicos que acentuam as divergências entre as perspetivas sociojurídica e económica (Braucher, 2006: 2). A primeira, onde avultam autores como Teresa Sullivan, Jean Braucher, Elizabeth Warren, Jay Westbrook, Robert Lawless ou Karen Gross, mostrou-se favorável desde sempre a um acesso alargado e sem peias à liquidação e ao perdão de dívidas, por considerar que a falência constitui a rede de proteção social que permite superar as fragilidades do Estado social. Daí a sua crítica feroz à revisão de 2005, pelas restrições que impõe ao acesso. A segunda, onde sobressaem os nomes de Todd Zywicki, Michelle White e Barry Adler, advoga a natureza securitária da falência e a necessidade de promover o seu uso eficiente, através do combate à fraude e ao risco moral dos devedores (Frade, 2007).

\footnotetext{
${ }^{12}$ Cf. o relatório de 2010 da Law Reform Commission intitulado Personal Debt Management and Debt Enforcement (http://www.lawreform.ie/_fileupload/Reports/rDebtManagementsFinal.pdf). 13 Em 1996, a VISA publicou o estudo Consumer Bankruptcy: Causes and Implications, onde destacava essa regressão do estigma social como um dos fatores que fizeram disparar o número de processos de insolvência nos EUA, entre 1981 e 1996.
} 
No cenário europeu a questão não tem suscitado tanto debate, o que não significa que o tema não seja pertinente para a análise dos quadros jurídicos da insolvência e do respetivo contexto. A diferença parece estar apenas na convicção declarada de que o estigma existe e se inscreve na própria lei através das constrições que são impostas aos devedores para conquistarem o perdão de dívidas. É pelo menos essa a convicção da americana Nathalie Martin (2005: 39), ao considerar mais adversas ao perdão e por isso mais estigmatizantes as leis europeias de matriz civilística, quando comparadas com o direito anglo-saxónico. Outros investigadores europeus sustentam a mesma posição (cf., por exemplo, Reifner et al., 2003), declarando que a sacralização das obrigações contratuais (absolutizadas no princípio civilista da pacta sunt servanda) impôs uma versão mitigada da filosofia do fresh start americano nas leis europeias continentais, que passa pela provação a que faz sujeitar o devedor para se desonerar das dívidas remanescentes e que levam o autor a defender que nas leis europeias, em lugar do princípio do fresh start, se consagrou um bem menos generoso, princípio do earned start. ${ }^{14}$ Já os autores suecos Carlsson e Hoff (2000: 311) chamam a atenção para o 'simbolismo sagrado' que representa a punição dos devedores na consolidação da consciência e da moral coletivas, que justifica que eles tenham que provar, perante a sociedade e o Estado, que merecem ser perdoados das suas dívidas.

\section{O estigma no direito português da insolvência}

Entre nós, o regime da falência está consagrado, desde 2004, no Código da Insolvência e Recuperação de Empresas (CIRE). Nele, o legislador entendeu introduzir duas soluções distintas para os indivíduos e as famílias, com diferentes propósitos e também diferentes impactos ao nível do estigma: o plano judicial de pagamentos e a liquidação dos bens com a exoneração do passivo restante.

\footnotetext{
${ }_{14}$ O princípio do fresh start ou da nova oportunidade é o esteio do direito da falência norte-americano. Imbuído da ideia de que o consumidor pessoa singular é, como qualquer agente económico, um sujeito que tem o direito a falhar e a recomeçar do novo sem ficar preso aos erros passados, o Bankruptcy Code (aprovado em 1978 e revisto em 2005), consagra, no seu capítulo 7, a possibilidade de uma liquidação dos bens penhoráveis do devedor para satisfação dos direitos dos credores, seguido de um perdão imediato das dívidas não pagas (straight bankruptcy). Deste modo, o sistema americano permite aos insolventes salvaguardar o rendimento futuro, ainda que à custa do sacrifício do património presente. Vários países europeus têm adotado este princípio nos seus direitos da falência, mas quase sempre de forma muito mitigada. Habitualmente o falido tem de esperar alguns anos até poder receber o perdão das dívidas remanescentes e sempre depois de, durante esse tempo, ter abdicado de uma parte dos rendimentos que foi obtendo em favor dos credores (Frade, 2007).
} 
Enquanto o plano de pagamentos está pensado para os insolventes de boa ou má-fé que, dispondo de rendimentos periódicos e não desejando liquidar os seus bens, entendam negociar com os credores, a exoneração é mais adequada a quem não disponha de rendimentos, disponha de rendimentos insuficientes para negociação com os credores ou pretenda liquidar a totalidade dos seus bens penhoráveis. Todavia, uma análise dos números das insolvências declaradas em Portuga ${ }^{15}$ aponta para uma utilização residual do plano de pagamentos, optando a maioria dos insolventes pela exoneração do passivo restante. O plano de pagamentos propicia uma menor estigmatização dos falidos, mas isso não é suficiente para o tornar uma solução popular ou sequer ajustada quando falamos de famílias onde o desemprego e a perda de condições laborais, bem como de apoios sociais, não permitem garantir um rendimento regular capaz de garantir os pagamentos exigidos por um plano. ${ }^{16}$

Olhando para a solução mais frequente, a da liquidação do património do insolvente com a possibilidade de obtenção de uma exoneração das dívidas remanescentes ao fim de cinco anos, é possível descortinar nela vários traços do laivo estigmatizador do direito falimentar português.

Uma leitura atenta do preâmbulo e das normas que regulam a exoneração do passivo restante na legislação portuguesa permite verificar que o fresh start propalado na parte preambular do diploma pelo legislador é na verdade um earned start, uma vez que os requisitos de acesso e manutenção da exoneração implicam não só a comprovação de que o devedor se encontra de boa-fé, como também de que cumpre um conjunto de deveres rígidos que poderão conduzir à exaustão psicológica e social do falido. Assim, ao contrário do que acontece no direito americano no qual se inspira, a exoneração não é imediata, mas concedida após a liquidação de todo o património penhorável do insolvente, juntamente com mais cinco anos de espera durante os quais deverá entregar os rendimentos disponíveis a um fiduciário (artigo 235. ${ }^{\circ}$ do CIRE).

\footnotetext{
$\overline{15}$ Veja-se o portal CITIUS, onde se encontram mais de 10000 despachos iniciais de exoneração do passivo restante.

${ }^{16}$ Não se discutem aqui as razões pelas quais o plano judicial tem tão pouco relevo face à solução liquidatória. Além da escassez e irregularidade de rendimentos que ameaçam atualmente a vida das famílias, uma cultura de alguns operadores judiciários mais favorável à liquidação, a concorrência de outros mecanismos não liquidatórios (como os Planos Especiais de Revitalização e o novo regime do PERSI, instituído pelo Decreto-Lei n. ${ }^{\circ} 227 / 2012$, de 25 de outubro), e mesmo o desconhecimento da opção, são alguns dos fatores que ajudarão a explicar a fraca adesão ao plano judicial de pagamentos previsto no CIRE. Para mais considerações sobre o plano de pagamentos, cf. Conceição (2013).
} 
O peso da sentença que declara a insolvência, com a consequente publicidade, transporta a falência de um plano privado para um plano público, de que terão conhecimento não só as pessoas mais próximas do falido, como o seu círculo pessoal e profissional, mas também a comunidade em geral, tendo em conta a amplitude dos meios publicitários, como o portal CITIUS e os editais colocados na residência do insolvente. ${ }^{17}$ Recentemente foi avançada a possibilidade da imposição, por Regulamento da União Europeia, da criação de um portal público de insolvências de pessoas singulares nos Estados-membros, o que, a confirmar-se, denota uma insensibilidade legal à questão da proteção da vida privada do insolvente e vem reforçar a ideia de que as autoridades públicas, através do quadro legal, utilizam mecanismos de exploração do estigma e da vergonha para, com poucos custos, aumentarem a conformidade dos comportamentos com o padrão prevalecente. ${ }^{18}$

Além disso, mesmo estando de boa-fé, a declaração de insolvência priva desde logo o insolvente dos poderes de administração e disposição dos seus bens penhoráveis (artigo 84. $\% 1$ do CIRE), desde esse momento até ao final do período de cinco anos de cessão do rendimento disponível, sendo que os poderes transitam para um administrador de insolvência nomeado pelo tribunal. Compreende-se a necessidade de supervisionar a atuação do devedor, nomeadamente quanto à gestão do património e à não ocultação de rendimentos. ${ }^{19}$ Mas o CIRE estabelece restrições não despiciendas à liberdade do insolvente gerir a sua vida pessoal e familiar, permitindo ao administrador e ao tribunal o sancionamento de decisões que deveriam apenas ter impacto na vida do insolvente. O insolvente não só terá de pedir autorização ao tribunal para efetuar certas despesas (por exemplo, despesas com enriquecimento profissional próprio ou de elementos do seu agregado familiar), como terá de ser autorizado a mudar de emprego, designadamente para um menos bem pago, mas mais adequado ao seu perfil.

\footnotetext{
${ }_{17} \mathrm{http} / / /$ www.jornaldenegocios.pt/economia/justica/detalhe/familias_insolventes_arriscam_lista_ negra_na_internet.html.

${ }^{18}$ Se se considerar que as instituições financeiras já dispõem, através da consulta à Central de Responsabilidades de Crédito do Banco de Portugal, de informação sobre os compromissos de crédito e os incidentes de pagamento dos clientes, não se compreende que interesses de terceiros se querem proteger com a criação de tal portal. Pelo contrário, advinham-se efeitos indesejáveis e ainda mais penalizadores para os indivíduos e famílias insolventes. Recorde-se que, por exemplo, na Suécia, uma lista semelhante disponível na internet e de fácil acesso a qualquer um tem servido para impedir a contratação laboral. Muitos empregadores desistem de contratar um trabalhador quando o seu nome aparece nessa lista de insolventes (Frade, 2007).

19 Neste aspeto, o regime holandês é ainda mais gravoso e verdadeiramente atentatório da dignidade dos falidos, ao prescrever que todo o correio do devedor é lido primeiramente pelo administrador judicial, a fim de evitar qualquer sonegação de rendimentos que possam servir para pagar aos credores.
} 
No entanto, os maiores indícios de que o estigma persiste na nossa lei falimentar vislumbram-se nas condições impostas e na duração do mecanismo da exoneração do passivo restante. Nos termos do artigo 239. ${ }^{\circ}$ do CIRE, após a liquidação dos bens, que pode durar pelo menos um ano, o juiz fixará as quantias que o insolvente deverá entregar aos credores durante cinco anos, constituindo rendimento disponível. No caso de não haver rendimento disponível, iniciar-se-á apenas uma contagem de prazo, a todos os títulos inútil, uma vez que os credores não vão receber qualquer quantia, que só se poderá justificar por uma conceção retaliatória do regime em face do insolvente.

Nos termos do . $^{\circ} 3$ do artigo $239 .^{\circ}$ do CIRE, não constituem rendimento disponível, entre outras, as quantias necessárias ao sustento minimamente digno do insolvente e do seu agregado familiar, não devendo exceder, salvo concordância do juiz, três salários mínimos nacionais, bem como as quantias necessárias ao exercício da atividade profissional do insolvente ou outras autorizadas pelo juiz. A lei, de forma aparentemente razoável, vem estabelecer a fixação de "mínimos de sobrevivência" ao insolvente, ainda que dependentes de decisão judicial. É, no entanto, necessário analisar esta aparente razoabilidade. Por um lado, a prática jurisprudencial revela muitas vezes a falta de sensibilidade para o problema, determinando-se as quantias acima referidas de um modo penalizador para o insolvente, não tendo em conta as suas necessidades concretas. Recorde-se que estamos perante insolventes de boa-fé, que não provocaram de forma intencional nenhuma lesão aos credores, pelo que os juízes deveriam atentar aos equilíbrios em jogo: se é verdade que os credores deverão ser ressarcidos, não é menos verdade que o insolvente, em termos constitucionais, tem direito à dignidade (artigo 26. ${ }^{\circ} \mathrm{CRP}$ ), não se podendo impor uma "pena" por via da exoneração, ou seja, um sacrifício ao seu património que inviabilize os seus direitos e necessidades fundamentais.

Por outro lado, chegando o juiz à conclusão de que não existe rendimento disponível, não faz qualquer sentido prolongar o período de cessão, pelo que a exoneração, neste caso, deveria ser imediata, uma vez que, para os credores, não sobrevirá qualquer pagamento. ${ }^{20}$ Deste modo, evitar-se-ia o prolongamento inútil do processo, com as consequentes restrições para o insolvente, ao impor-lhe deveres e limitações que tão pouco trazem qualquer benefício aos credores.

Ainda no que concerne às medidas impostas ao devedor no período de cessão, o artigo $239 .^{\circ}$ n. ${ }^{\circ} 4$ do CIRE estabelece um conjunto de deveres que

${ }^{20}$ Para aferir da opinião dos juízes, veja-se o Relatório de Avaliação Sucessiva do Regime Jurídico da Insolvência e Recuperação de Empresas (2009: 37-39), disponível em www.dgpj.mj.pt. 
deverão ser cumpridos até ao final do período de cessão, sob pena de cessação antecipada, recusa ou revogação da exoneração. Assim, o insolvente fica obrigado a não ocultar quaisquer rendimentos; a comunicar ao tribunal e ao fiduciário, sempre que requerido, de que rendimentos dispõe; a exercer uma profissão remunerada, não a abandonando sem motivo legítimo; a procurar emprego quando desempregado, não recusando empregos para os quais seja apto; a entregar ao fiduciário todas as quantias fixadas pelo tribunal, logo que recebidas; a informar o tribunal e o fiduciário das mudanças de domicílio ou de emprego, e ainda das diligências para encontrar trabalho; a não efetuar quaisquer pagamentos diretamente aos credores. Estes deveres mostram bem como o regime da insolvência comprime significativamente a liberdade e os direitos fundamentais do insolvente, muito para lá da venda forçada do seu património. Conquanto, como se referiu, a execução por dívidas já não incida sobre a pessoa do devedor, mas sobre o seu património, não deixa por isso de refletir-se de modo inexorável sobre a sua esfera pessoal de direitos.

Mesmo não incumprindo quaisquer regras, o período temporal do processo, longo, leva a um desgaste psicológico e social significativo, estando o insolvente privado de uma vida normal por vários anos, em nome de um cumprimento, por vezes residual, das suas dívidas. $\mathrm{O}$ insolvente fica apartado do mercado, não pode obter crédito, não pode livremente fazer escolhas relativas à sua profissão, educação e bem-estar. E à medida que o tempo do processo vai correndo, o alívio que certamente sentiu num primeiro momento em que deixou de ser assediado constantemente pelos credores, esfuma-se na sua impotência para reassumir o controlo da sua vida financeira, que não lhe pertence de todo. Como se não bastasse, quando consegue chegar ao fim da provação, incorre o risco de não receber a almejada exoneração. No final dos cinco anos, a exoneração poderá ser recusada pelo tribunal, nos termos do artigo 244 n. ${ }^{\circ} 2$ do CIRE, com fundamento, por exemplo, na violação dos deveres atrás apontados. Estas considerações, feitas pelo juiz com suporte na informação dos credores e do fiduciário, deverão ser absolutamente pautadas por princípios de proporcionalidade e razoabilidade, sob pena de inviabilizar o espírito da lei e conduzir a um resultado muito desastroso para o insolvente. Para além disso, até um ano após a concessão definitiva da exoneração, esta pode ainda ser revogada, nos termos do artigo $246 .^{\circ}$ n. ${ }^{\circ} 1$ do CIRE, com fundamentos quase idênticos, estabelecendo-se uma espécie de liberdade condicional ao devedor. Verifica-se pois uma incompreensível proteção dos credores, impedindo o insolvente de retomar a sua vida normal e gorando-lhe as suas expectativas (Conceição, 2013; Serra, 2012). 


\section{Conclusão}

Ao longo destas páginas procurou demonstrar-se que a interação entre o direito e o estigma não se confina a uma atitude de condenação e superação deste. Se é certo que os referenciais constitucionais e legais se declaram abertamente contra atitudes e comportamentos discriminatórios dos indivíduos ou de certos grupos e lhes proporcionam mecanismos processuais para os combater pessoalmente, não é menos verdade que, em determinados domínios da vida social, o direito tem sabido utilizar a seu favor a perceção estigmatizante em relação a certas pessoas ou comunidades. A estigmatização que historicamente acompanhou os falidos e que não só se fez sentir nas relações sociais, mas também permeou as regras do direito e da religião, está hoje mais esbatida, mas não desapareceu de todo. Aliás, o risco de ser o próprio direito a manter vivo o estigma social em torno da falência parece pairar no ar, a fazer fé na iniciativa legislativa europeia de levar por diante a exibição, na praça pública da internet (a maior e a mais pública que porventura já existiu), da vergonha de não se honrar os compromissos.

\section{Referências bibliográficas}

Antunes, José Engrácia (1993), "Algumas notas sobre a determinação da medida judicial da pena no Código Penal Português", Revista da Ordem dos Advogados, 53 (II), 427-520. ASB (2004), Overindebtedness as a Barrier to Labour Market Access in Europe. Challenges and Ways Forward. Salzburgo: ASB Schuldnerberatungen GmbH.

Braithwaite, John (1989), Crime, Shame and Reintegration. Cambridge: Cambridge University Press.

Braucher, Jean (2006), "Theories of Over-Indebtedness: Interaction of Structure and Culture”, Arizona Legal Studies Discussion Paper, no. 06-04. Consultado a 12.09.2013, em http://ssrn.com/abstract=826006.

Burris, Scott (2006), "Stigma and the Law", The Lancet, 367(9509), 529-531.

Burris, Scott (2008), "Stigma, Ethics and Policy: A Response to Bayer", Social Science E Medicine, 67(3), 473-475.

Canadian Mental Health Association (2013), Stigma and Discrimination. Consultado a 15.09.2013, em http://ontario.cmha.ca/mental-health/mental-health-conditions/ stigma-and-discrimination/.

Carlsson, Bo; Hoff, David (2000), "Dealing with Insolvency and Indebted Individuals in Respect to Law and Morality", Social \& Legal Studies, 9(2), 293-317.

Conceição, Ana Filipa (2013), "Disposições específicas da insolvência de pessoas singulares no Código da Insolvência e da Recuperação de Empresa", in Catarina Serra (org.), I Congresso de Direito da Insolvência. Coimbra: Almedina, 29-62. 
Dias, Jorge de Figueiredo (1983), “Os novos rumos da política criminal e o direito penal português do futuro", Revista da Ordem dos Advogados, 43, 5-40.

Efrat, Rafael (2006a), "The Evolution of Bankruptcy Stigma”, Theoretical Inquiries in Law, 7, 365-393.

Efrat, Rafael (2006b), "Bankruptcy Stigma: Plausible Causes for Shifting Norms”, Emory Bankruptcy Developments Journal, 22, 482-519.

Frade, Catarina (2007), Regular o sobreendividamento. Dissertação de doutoramento. Coimbra: FEUC.

Frade, Catarina (2012), "Bankruptcy, Stigma and Rehabilitation”, ERA Forum, 13(1), 45-57.

Friedman, Lawrence Meir (1975), The Legal System: A Social Science Perspective. New York: Russell Sage Foundation.

Galbiati, Roberto; Garoupa, Nuno (2007), "Keeping Stigma Out of Administrative Law: An Explanation of Consistent Beliefs", Supreme Court Economic Review, 15(1), 273-283.

Goffman, Erving (1963), Stigma: Notes of the Management of Spoiled Identity. New York: Simon and Schuster.

Haas, Oliver (2006), "Overindebetdness in Germany”, ILO Working Paper n. 44. Genebra: International Labour Office.

Link, Bruce; Phelan, Jo (2006), "Stigma and its Public Health Implications", The Lancet, 367(9509), 528-529.

Marques, Maria Manuel (org.) (2000), O endividamento dos consumidores. Coimbra: Almedina.

Martin, Nathalie (2005), “The Role of History and Culture in Developing Bankruptcy and Insolvency Systems: The Perils of Legal Transplantation”, Boston College International and Comparative Law Review, XXVIII(1), 1-77.

Mols, Yvana (2012), "Bankruptcy Stigma and Vulnerability: Questioning Autonomy and Structuring Resilience”, Emory Bankruptcy Developments Journal, 29(1), 289-331.

Nussbaum, Martha (2004), Hiding From Humanity: Disgust, Shame, and the Law. Princeton: Princeton University Press.

Porter, Katherine M. (2010), "Life after Debt: Understanding the Credit Restraint of Bankruptcy Debtors”, American Bankruptcy Institute Law Review, 18(1), 1-42.

Reifner, Udo; Kiesilainen, Johanna; Huls, Nik; Springeneer, Helga (2003), Consumer Overindebtedness and Consumer Law in the European Union. Hamburgo: IFF.

Serra, Catarina (2012), O regime português da insolvência. Coimbra: Almedina.

Sullivan, Teresa; Warren, Elizabeth; Westbrook, Jay Lawrence (2000), The Fragile Middle Class. Americans in Debt. New Haven: Yale University Press.

Tabb, Charles (2002), Bankruptcy Anthology. Cincinnati: Anderson Publishing.

Tabb, Charles (2005), "The Brave New World of Bankruptcy Preferences”, American Bankruptcy Institute Law Review, 13, 225-256. 
Thorne, Deborah; Anderson, Leon (2006), "Managing the Stigma of Personal Bankruptcy”, Sociological Focus, 39(2), 77-97.

Warren, Elizabeth; Westbrook, Jay Lawrence; Sullivan, Teresa (2006), Less Stigma or More Financial Distress: An Empirical Analysis of the Extraordinary Increase in Bankruptcy Filings. Consultado a 20.10.2013, em http://ssrn.com/abstract=903355. White, Michelle (2007), "Personal Bankruptcy Law: Abuse Prevention versus Debtor Protection", American Law E Economics Association Annual Meetings, Paper n. ${ }^{\circ}$ 49. Consultado a 20.10.2013, em http://law.bepress.com/cgi/viewcontent. cgi? article $=1902 \&$ context $=$ alea.

Ziegel, J. (2006), "Facts on the Ground and Reconciliation of Divergent Consumer Insolvency Philosophies”, Theoretical Inquiries in Law, 7(2), 299-321. 